\title{
O GATO DE SCHRÖDINGER não ESTÁ VIVO E MORTO ANTES DA MEDIÇÃO: SOBRE A INTERPRETAÇÃO DOS RESULTADOS QUÂNTICOS
}

\author{
Décio Krause $\mathrm{K}^{1,2}$
}

\begin{abstract}
Muitos textos de divulgação que falam da mecânica quântica fazem referência ao "paradoxo" do gato de Schrödinger, comentando que, antes da medida do estado do sistema, o gato encontra-se vivo e morto ao mesmo tempo. Outros dizeres referem-se a que uma partícula pode estar em dois (ou mais) lugares ao mesmo tempo, que ela passou por duas fendas simultaneamente, ou ainda que percorreu dois caminhos de uma só vez, e que "interferiu consigo mesma". Na opinião deste autor, tratam-se de exageros conceituais, que podem conduzir o leitor não especializado ao erro e a imaginar situações que nada têm a ver com a mecânica quântica propriamente dita, entendida do modo como o fazemos neste artigo. Este texto de caráter geral, sem mencionar essas fontes, tem a intenção de esclarecer ou ao menos de questionar esses e outros pontos polêmicos na fala comum sobre os resultados da mecânica quântica.
\end{abstract}

\section{Introdução}

"Cats seem to play an important role in physics."

B. Kanitscheider (1992)

Quando nos deparamos com situações inusitadas, com as quais nunca tivemos contato anterior, tendemos a procurar explicações dentro dos contextos que nos são familiares. Assim, se vemos uma imagem difusa de um animal, na tentativa de descobrir do que se trata, procuramos em nossos arquivos aqueles animais conhecidos que em nossa opinião mais se aproximam daquilo que vimos difusamente. Muitas vezes, cometemos o erro de achar que o tal animal é de algum tipo, e podemos estar equivocados. Isso parece bastante evidente para qualquer um que se ocupe a pensar sobre o assunto, e acontece também com os resultados que obtemos em nossas teorias científicas, em especial nas teorias da física. A física quântica é um dos campos do saber que mais nos apresentam resultados que nos parecem totalmente estranhos, e as explicações que tentamos dar, tomando por base o que (supostamente) conhecemos, a física clássica, via de regra não são satisfatórias. Aliás, foi precisamente por esse motivo que a física quântica surgiu, incialmente com a hipótese de quantização de Planck para explicar os resultados observados na radiação de um corpo negro, pois a teoria vigente não explicava os fenômenos observados. ${ }^{3}$

\footnotetext{
${ }^{1}$ Departamento de Filosofia. Universidade Federal de Santa Catarina. Pesquisador do CNPq. Email: deciokrause@gmail.com.

2 Agradeço a Alexandre Costa-Leite pelo convite para escrever este artigo em comemoração aos cinco anos do Seminário Permanente Lógica no Avião, realizados na Universidade de Brasília.

${ }^{3}$ Há muitos textos excelentes de história da física quântica, como Baggott (2013), Jammer (1974), Kumar (2009).

DOI:10.21452/LnA_serie_n_v01_book_seminario-logica-no-aviao-2013-2018_decio-krause_p.104-122
} 
Para discutir esse assunto ao menos de forma introdutória e para colocar nosso ponto de vista de que nos enganamos também na interpretação dos resultados em mecânica quântica, e igualmente visando alertar o leitor para equívocos, é conveniente distinguir entre uma formulação de uma teoria científica (aqui ficaremos restritos à física quântica) ${ }^{4}$ e uma interpretação dessa formulação, a qual nos fornece, por assim dizer, uma visão de mundo. Há muitos modos de se formular uma MQ (em Styer et al. 2002, nove alternativas são apresentadas) que são, ao que tudo indica, equivalentes empiricamente (ainda que isso seja discutível), e a cada uma delas pode-se associar (pelo menos em princípio) várias interpretações.

A formulação padrão, usualmente considerada pelos filósofos, faz uso da teoria dos espaços de Hilbert, tendo sido originada com von Neumann na década de 1930. Quanto às interpretações, a considerada "padrão" é a dita "de Copenhague", devida principalmente a Bohr, Heisenberg, Born, Jordan e Pauli, ainda que haja variações mesmo entre eles. Nesse formalismo, que é o que consideremos exceto se dito explicitamente o contrário, os estados dos sistemas físicos são considerados e há "observáveis" que podem ser medidos; quando um observável é medido, considerando-se um certo estado (descrito por um vetor ou por uma função de onda), um valor que representa uma probabilidade é obtido. Assim, o que se vê é um tratamento matemático que tem como conceitos primitivos as noções de estado e observável; os sistemas físicos propriamente ditos, como partículas elementares, átomos e moléculas, aparecem apenas implicitamente, a sua natureza sendo relegada às interpretações.

O formalismo, ou os formalismos (para empregar um termo caro aos físicos) é bem entendido. O problema maior aparece quando se tenta entender o que está acontecendo. Aí é que aparecem as discrepâncias para com aquilo que conhecemos, pois as entidades tipicamente quânticas parecem se comportar de um modo totalmente inusitado e estranho à física clássica e à nossa intuição. O assunto se complica mais ainda quando explicações destinadas ao grande público são postas, quando (na opinião deste autor) muitos erros são veiculados. Analisaremos abaixo alguns deles, reduzindo o formalismo matemático a um mínimo. ${ }^{5}$

\section{O formalismo}

Segundo o formalismo padrão via espaços de Hilbert, se um sistema físico tem a possibilidade de estar em dois estados, descritos por vetores $\left|\psi_{1}\right\rangle$ e $\left|\psi_{2}\right\rangle$, postula-se que qualquer combinação linear desses "estados" é também um estado possível do sistema, digamos

$$
|\psi\rangle=a\left|\psi_{1}\right\rangle+b\left|\psi_{2}\right\rangle,
$$

com $a$ e $b$ números complexos tais que $|a|^{2}+|b|^{2}=1$ (ver mais abaixo). Um tal estado é o que se denomina de superposição dos estados (descritos por) $\left|\psi_{1}\right\rangle$ e $\left|\psi_{2}\right\rangle$ (os abusos de linguagem serão cometidos doravante, como a identificação do vetor com o estado do sistema).

\footnotetext{
4 Por "física quântica" entendemos um grupo de teorias que prioritariamente lidam com o nosso "mundo microscópico", ainda que, no limite, a física clássica, que lida com os objetos do nosso quotidiano, se reduza à quântica. Dentre essas teorias, podemos discernir entre a mecânica quântica não relativista (MQ), a mecânica quântica relativista, que incorpora a relatividade restrita (MQR).

5 Um excelente livro para o público geral, que mostra as esquisitices do mundo quântico é Gilmore (1998). Textos mais bem elaborados e escritos em português, constam dos dois volumes de Pessoa Jr. (2003) e (2006) e de Chibeni (1997).
} 
Um caso particular de uma superposição é quando temos o emaranhamento de dois sistemas; se temos dois estados possíveis, $A$ e $B$ e dois sistemas, descritos por $\left|\psi_{1}\right\rangle$ e $\left|\psi_{2}\right\rangle$, um sistema emaranhado é um vetor da forma (o sinal "+" é usado para bósons e o "-" para férmions): 6

$$
\left|\psi_{12}\right\rangle=\frac{1}{\sqrt{2}}\left(\left|\psi_{1}\right\rangle^{A} \otimes\left|\psi_{2}\right\rangle^{B} \pm\left|\psi_{2}\right\rangle^{A} \otimes\left|\psi_{1}\right\rangle^{B}\right),
$$

onde o coeficiente $1 / \sqrt{2}$ indica que, quando medirmos alguma coisa sobre o sistema conjunto, obtemos $|a|^{2}=|b|^{2}=1 / 2$ de encontrarmos o sistema em um dos estados da superposição acima, ou seja, $\left|\psi_{1}\right\rangle^{A} \otimes\left|\psi_{2}\right\rangle^{B}$ ou $\left|\psi_{2}\right\rangle^{B} \otimes\left|\psi_{1}\right\rangle^{A}$, os quais indicam respectivamente o sistema é tal que o primeiro componente está no estado $A$ e o segundo componente está no estado $B$ ou que o primeiro está no estado $B$ e o segundo em $A$. O produto " $\otimes$ " dos vetores indica o produto tensorial, uma operação que se pode definir entre espaços e entre vetores. A questão é saber o que indica o estado $\left|\psi_{12}\right\rangle$ antes do sistema ser medido. ${ }^{7} \mathrm{~A}$ teoria diz que, depois da medição de um observável, como spin ou posição, do sistema no estado $\left|\psi_{12}\right\rangle$, o sistema entra imediatamente em um dos estados componentes. Há vários modos de se denominar essa alteração, a principal chamada de colapso da função de onda (ou do vetor de estado).

Suponha que, depois do colapso, tenhamos obtido o estado $\left|\psi_{1}\right\rangle^{A} \otimes\left|\psi_{2}\right\rangle^{B}$. Aparentemente, isso nos indicaria que o primeiro sistema está no estado $A$ e que o segundo sistema está no estado $B$, havendo portanto uma distinção entre eles. Mas não é assim. Devido a problemas com a identidade dos sistemas quânticos, algo do qual falaremos brevemente à frente, não há como distinguir um sistema do outro se eles forem do mesmo tipo (digamos, ambos sendo elétrons). Isso é devido a um postulado adicional chamado de Postulado da Indistinguibilidade (French \& Krause 2006, passim), que diz exatamente isso: a medida de um observável para um sistema (podendo comportar vários subsistemas) em um certo estado é o mesmo (dá a mesma probabilidade) antes e depois de uma permutação dos mesmos. Ou seja, pernutações (de sistemas de mesmo tipo) não são observadas. Que isso deve ser assim tinha sido apontado já por John Dalton em 1808 na origem da química moderna (veja Krause \& Arenhart 2018); não pode haver diferenças entre átomos da mesma substância, ou entre seus componentes, desde que sejam de mesmo tipo (esses foram descobertos depois, como elétrons, protons e outros.)

Mas, antes da medição, os sistemas quânticos estão em um estado que é uma superposição de outros estados. ${ }^{8}$ Isso tudo é matematicamente claro, e o cálculo das probabilidades é algo que também se sabe fazer. A matemática funciona muito bem. ${ }^{9}$ O problema surge quanto se tenta interpretar a superposição. Muitos dizem, erroneamente na opinião deste autor, que o sistema está em todos os estados superpostos simultaneamente. Isso será melhor explicado abaixo. Essa suposição é calcada em conceitos advindos da física clássica, e não temos (ainda) como exprimir em palavras o que o formalismo matemático

\footnotetext{
${ }^{6}$ Bósons e férmions são as duas grandes classes de partículas. Apesar do formalismo matemático ser compatível com a existência de outros tipos de partícula, as que se conhecem caem em uma dessas duas categorias; veja French \& Krause (2006), §3.8.

$7 \mathrm{O}$ vetor (2) pode ser abreviado por $\left|\psi_{12}\right\rangle=\left|\psi_{1}^{A} \psi_{2}^{B}\right\rangle \pm\left|\psi_{2}^{A} \psi_{1}^{B}\right\rangle$, omitindo-se inclusive o coeficiente $\frac{1}{\sqrt{2}}$.

8 Insistindo, matematicamente uma superposição de estados nada mais é do que uma combinação linear de vetores que representam estados possíveis. Uma combinação linear de vetores é um outro vetor que equivale a uma soma desses vetores, cada um deles multiplicado por uma constante.

${ }^{9}$ Há no entanto outro problema relacionado ao conceito de probabilidade. Mas essa é outra história.
} 
está contando tão claramente. O erro de se tentar usar a linguagem usual, calcada na física clássica, resulta do fato de que, como dizia Paul Dirac, essa situação não pode ser descrita por essa linguagem (Dirac 1967, Cap.1), com a qual estamos mais acostumados. Qualquer tentativa de explicar o que está acontecendo utilizando conceitos comuns conduz a absurdos como afirmar que, previamente à medição do estado do sistema, ambos os estados estão presentes na descrição do sistema conjunto, ou seja, que ele está em ambos os estados ao mesmo tempo. Vamos explicar isso a seguir, utilizando o célebre exemplo do gato de Schrödinger, amplamente discutido na literatura.

Fica aqui a mensagem deste artigo. É patente que pode-se associar ao formalismo matemático da mecânica quântica uma plêiade de interpretações não equivalentes e não há, a princípio, qualquer argumento que faça uma delas prevalecer sobre as demais. No entanto, acreditamos que se não podemos agir "positivamente", podemos fazê-lo "negativamente": podemos assegurar que pelo menos um modo de se interpretar os resultados quânticos é equivocado, a saber, aquele que supõe que, previamente à medição, o sistema se encontra simultaneamente em todos os estados possíveis. Veremos isso a seguir com mais detalhes.

\section{O gato}

Talvez o melhor exemplo que se possa usar para atestar os equívocos mencionados é o caso do célebre gato de Schrödinger. Em 1935, Erwin Schrödinger criou um experimento mental para enfatizar os aspectos contra-intuitivos das superposições e da dominante (à época) "interpretação de Copenhague". Ele imaginou o experimento envolvendo um objeto macroscópico, um gato, justamente para enfatizar o seu ponto. Porém, saliente-se, não se observam objetos macroscópicos em superposição, mas isso ocorre com objetos à escala quântica. ${ }^{10}$

Abreviadamente, a questão é a seguinte. Imagine um gato preso em um quarto hermeticamente fechado no qual há um frasco de veneno e uma amostra de material radioativo que tem 50\% de possibilidade de emitir uma partícula (decair) no decorrer de uma hora. Se a partícula for emitida, um mecanismo é ativado de modo que o frasco de veneno é quebrado, o veneno é liberado e o gato morre. Se nenhuma partícula for emitida, o frasco continua intacto e o gato permanece vivo. Para saber como está o gato, ou seja, qual é o seu estado depois de uma hora, o cientista abre a porta do quarto e observa o gato. Isso corresponde a uma medição, a medir o estado do gato exatamente no momento em que o cientista abre a porta. O sistema é preparado de forma que há probabilidade de $1 / 2$ de o cientista encontrar o gato vivo e 1/2 de encontrá-lo morto (essa possibilidade é correspondida empiricamente). O estado do gato previamente à abertura da porta é descrito por um vetor semelhante a (2), expressando uma soma (ou subtração) de um vetor (um produto tensorial) que representa a situação de que o material não decaiu e o gato está vivo com outro vetor representando a situação de que o material decaiu e o gato está morto.

Segundo a interpretação usual (e equivocada), antes da medição o gato está vivo e morto ao mesmo tempo, partilhando, a uma só vez, de ambos os estados possíveis.

10 Quando os sistemas têm muitos elementos quânticos, como um gato, que é composto de trilhões de átomos e moléculas, a ação do meio ambiente ocasiona um fenômeno ao qual os físicos dão o nome de decoerência, ou seja, o sistema "perde" a sua "coerência" quântica, comportando-se como um "sistema clássico". Veja Schlosshauer (2004). 
No caso, temos uma situação particular de uma superposição, denominada de emaranhamento, que Schrödinger chegou a dizer (em 1935) ser a característica distintiva da mecânica quântica, sem similar na física clássica (Schrödinger 1980).

Experimentos que simulam a situação do gato de Schrödinger podem ser realizados ao nível quântico, como tem sido comum nos dias de hoje, colocando-se sistemas quânticos em estados emaranhados. Essa é, na verdade, uma das maiores revoluções proporcionadas pela MQ, possibilitando, dentre outras coisas, a computação quântica e as discussões sobre a informação quântica.

3.1 Ontologia. Mas, antes da medição, qual a situação do gato? Antes de discutir isso, é preciso conceder que podemos falar do gato, ou seja, que o nosso uso da mecânica quântica não é meramente instrumentalista, como advogam alguns físicos a começar por Niels Bohr, mas que há algum tipo de ontologia associado à teoria. ${ }^{11}$ É sabido que Bohr via com suspeição a possibilidade de uma realidade independente dos fenômenos quânticos que se assemelhe àquela descrita por uma ontologia aos moldes clássicos, de objetos tais como os descritos pela física clássica. ${ }^{12}$ Assim, temos que adotar uma postura diferente e admitir que, mesmo antes da medição, há algo do que podemos falar. A questão ontológica é especificar em que consiste esse algo, e a resposta não é única. Mas esse é outro assunto. ${ }^{13}$

Para os instrumentalistas, a mecânica quântica não nos permite falar de gatos ou de partículas; ela é meramente uma teoria matemática que nos permite computar probabilidades, como a de que o estado do sistema sendo uma superposição "gato+material radioativo", após a medição, resulte algo como

$$
\mid \text { gato vivo }\rangle \otimes \mid \text { não houve decaimento }\rangle,
$$

o que atestaria que não houve decaimento e o gato continua vivo. Só isso, nada mais.

3.2 Superposições. Vamos ser mais precisos. Antes da medição (ou seja, do cientista abrir a porta), o estado do sistema conjunto gato mais material radioativo é descrito por um vetor da forma $A+B$, onde $A$ é o vetor que indica o estado em que o material radioativo não decaiu e o gato está vivo, enquanto que $B$ é o vetor que indica a situação em que o material emitiu radiação e o gato está morto.

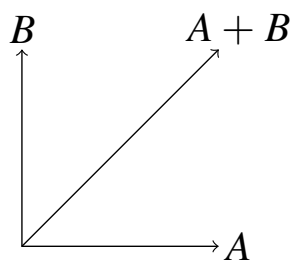

$11 \mathrm{Na}$ verdade, como argumentaremos abaixo, há várias ontologias possíveis de serem associadas a uma teoria.

12 Alguns autores creditam a Bohr uma visão empirista da MQ. Outros, como Folse Jr (Folse Jr 1986) e o presente autor, preferem vê-lo não como rejeitando um realismo (exceto aquele no sentido de Einstein - ver a seção 3.3, mas como possibilitando a admissão de uma realidade de entidades distintas daquela apregoada pela física clássica. Ou seja, Bohr poderia ser um realista de entidades (no sentido de Hacking 1983), mas de entidades de "outro" tipo, aquelas "tipicamente quânticas".

13 Com efeito, a natureza dessas entidades vai depender da interpretação que se adote. À formulação da MQ devida a David Bohm, uma "interpretação clássica" pode ser associada, no sentido de que as entidades quânticas não diferem essencialmente daquelas descritas pela física clássica; para uma distinção entre ontologia clássica e ontologia quântica, ver Krause et al. (2012). 
Fig. 1 - A soma de dois vetores ortogonais não nulos produz um terceiro vetor diferente de ambos.

O erro frequente na interpretação desse resultado é não considerar que a soma $A+B$ é um terceiro vetor, que indica uma superposição dos estados $A$ e $B$, e que é distinto de ambos (supostos não nulos). Aqui acaba a matemática, entrando a interpretação. No caso do gato, o que $A+B$ quer dizer? Lembre mais uma vez de Dirac: isso não pode ser explicado em termos clássicos, ou seja, não há analogia possível com algo que conhecemos em nosso dia a dia. Se podemos falar no gato (deixando de lado o instrumentalismo), o seu estado é descrito pela superposição de $A$ e $B$, e não por esses vetores isoladamente, e muito menos pela sua "conjunção", que indicaria que ele estaria simultaneamente nos dois estados. É errado portanto dizer que o gato está vivo (o que exigiria que o seu estado fosse $A$ ) ou que está morto (o que exigiria que seu estado fosse $B$ ), e muito menos "ao mesmo tempo", o que exigiria que considerássemos a sua conjunção, e não a sua soma! $\mathrm{O}$ estado do gato é dado pelo vetor $A+B$, portanto nem por $A$ e nem por $B$, mas pelo terceiro vetor, que não é uma conjunção lógica, mas uma soma vetorial. ${ }^{14}$

$\mathrm{O}$ estado do gato, previamente à medição, portanto, é descrito pelo vetor $A+B$. Depois da medição, esse vetor soma colapsa (segundo a interpretação dominante) por um motivo que ninguém conhece, em um dos estados componentes, ${ }^{15}$ mas antes disso temos somente a probabilidade de que o estado resultante será um ou outro, nunca ambos. Fiquemos portanto com a seguinte mensagem: previamente à medição, o gato não está vivo $e$ morto: não há contradição nesse caso.

Da mesma forma, muitos textos se referem à possibilidade de uma partícula (ou melhor, um sistema quântico) estar em dois ou mais lugares ao mesmo tempo (mais na seção 5). Outro equívoco: esses sistemas não têm posição em sentido usual, mas o que poderíamos chamar de estados-posição. Antes da medição, o sistema está em uma superposição de estados que indicam, por meio de uma probabilidade, onde ele (reparem no nosso discurso, tendo que nos referi a "ele" como se fosse um objeto descrito pela física clássica) poderá aparecer depois que sua posição for medida, por exemplo, em um determinado lugar em um anteparo que recebe as partículas. Portanto, guarde isso também: sistemas quânticos não podem estar em mais de uma posição a um só tempo. A linguagem não é precisa, mas a matemática é bem clara, expressa pela superposição de todas as posições possíveis e suas probabilidades, e não de uma conjunção de quaisquer coisas que indiquem posições.

3.3 O realismo de Einstein. Fizemos referência acima ao fato de que Bohr contestava algumas posições de Einstein. Este acreditava na existência de uma realidade externa calcada nos conceitos de separabilidade e localidade (Howard 2017). Para ele, sistemas

${ }^{14}$ Dizendo isso, somos contrários à interpretação paraconsistente da MQ dada por da Costa e de Ronde (2013), que admitem a possibilidade de haver uma contradição no caso do gato previamente à medição. Discutimos a posição desses autores em Arenhart \& Krause (2016). Como dissemos na Introdução, não obstante em geral não podermos optar por uma interpretação exceto por motivos nada objetivos, essa é uma interpretação que em nossa opinião não pode ser aceita. Se a MQ admite alguma contradição, certamente ela não está em situações como as descritas aqui e abaixo. No entanto, veja a seção 4 .

15 Na interpretação dos muitos mundos (Wallace 2012), quando há a medição, o universo se divide em vários, não havendo o colapso; no caso do gato, em dois, um no qual o gato está vivo e outro no caso em que o gato está morto. Mas mesmo assim não há qualquer contradição, pois o gato nunca está vivo e morto em um mesmo mundo. 
localizados em posições distintas do espaço, a uma distância $d>0$ um do outro, deveriam ser considerados como sistemas físicos distintos e qualquer ação em um deles só poderia influenciar o outro se algum tipo de informação fosse transmitida, como um fóton, o que (pela relatividade restrita) não pode acontecer imediatamente, devido ao fato da velocidade da luz ser finita. A mecânica quântica, por outro lado, considera que mesmo sistemas separados podem ser considerados como um só sistema, uma vez que tenham interagido no passado. Em tais sistemas emaranhados, a ação sobre um deles permite que se saiba fatos do outro imediatamente (isso, no entanto, não viola a relatividade restrita). ${ }^{16}$

O que se chama de "realismo de Einstein", no entanto, é a crença de que todos os observáveis físicos que um sistema têm valores bem determinados em qualquer instante de tempo como na física clássica, ainda que não os conheçamos objetivamente. Que isso não é assim na MQ é fato bem conhecido, em especial devido a um teorema demonstrado em 1967 por Simon Kochen e Ernst Specker (antecipado por John Bell em 1966), mas isso não será comentado aqui. Além disso, para Einstein, a física deve ser determinista: dada a situação de um sistema em um dado instante, as equações devem nos possibilitar conhecer a situação do sistema em qualquer instante de tempo posterior (ou anterior). A formulação de Copenhague, pelo contrário, não é determinista nesse sentido porque não consegue prever com $100 \%$ de segurança o que acontece com o estado do sistema depois de uma medição (depois do "colapso"), oferecendo apenas probabilidades. ${ }^{17}$

\section{A negação quântica}

O problema parece depender do modo como se entendem "morto" e "vivo" (a negação de "morto"), no caso do gato. Usualmente, entende-se por contradição a conjunção de duas proposições (sentenças ou fórmulas), uma das quais sendo a negação da outra. Se usarmos " $"$ " para representar a negação, " $\wedge$ " para a conjunção e " $S$ " para denotar uma sentença, uma contradição é uma sentença da forma " $S \wedge \neg S$ ". As sentenças " $S$ " e " $\neg$ " dizem-se contraditórias. Na linguagem da maioria das lógicas, como no caso da lógica clássica, se temos ambas $S$ e $\neg S$, podemos formar a sua conjunção e obter $S \wedge \neg S$. ${ }^{18}$ Por outro lado, se temos uma contradição, podemos derivar ambas as sentenças. Repare que não faz sentido falar "ao mesmo tempo" a não ser como abuso de linguagem (ou que tenhamos algum tipo de lógica temporal). A lógica clássica, assim como a maioria dos sistemas lógicos usuais, não envolve a noção de tempo.

Assim, insistamos nisso, se temos uma contradição, temos que ter as duas situações descritas pelas sentenças $S$ e por sua negação, $\neg S$. Dito informalmente, ambas têm que ser "verdadeiras" (deixemos o sentido do vocábulo "verdade"implícito, interpretando-o informalmente). Portanto, no caso do gato de Schrödinger, se dizemos que (previamente à medição) o gato está vivo $e$ morto, temos que dispor dos dois estados vivo e morto como

16 Não é nosso objetivo discutir esse importante ponto aqui. Veja Kumar (2009) sobre o célebre debate entre Bohr e Einstein sobre o tema. O importante é saber que é errado dizer que a medição em um sistema infuencia o outro; nenhuma "influência" existe pelo motivo explicado. O que acontece é algo tipicamente quântico; a medição em um sistema permite saber o que acontece com o outro, sem que qualquer mensagem tenha sido emitida. Este é reconhecidamente o maior dos mistérios quânticos, mas é um fato mais do que estabelecido empiricamente nos dias de hoje.

17 Um excelente texto geral sobre a filosofia de Einstein é Howard (2017); ver também Fine (1986).

18 Doravante não faremos mais a distinção entre uso e menção. 
estados atuais do gato, o que não ocorre. O seu estado, como vimos, é descrito por uma superposição, uma soma vetorial, e não por uma conjunção lógica.

Que isso é assim já foi mencionado por importantes autores, como Beltrametti \& Cassinelli (1981, pp.220-1) e por Bas van Fraassen (1974, p.229) no contexto das lógicas quânticas (mas veja também Aerts et al. 2000). Tanto os dois primeiros como o terceiro mencionam que a negação em mecânica quântica deve ser vista não como contraditoriedade (uma sendo verdadeira se e somente se a outra for falsa), mas como o que van Fraassen chamou de choice negation.

4.1 Negações clássica e quântica. Para van Fraassen (assim como para Beltrametti e Cassinelli), a choice negation permite que sejam discernidos os conceitos de falsidade e de não-verdade, que são tomados como equivalentes com a negação usual, que van Fraassen denomina de exclusion negation (uma sentença exclui a outra). Na física quântica, por outro lado, podem haver situações em que tanto uma quanto a outra possam ser falsas, mas não possam ser ambas verdadeiras, como por exemplo quando o estado é uma superposição de estados. Explicando melhor: no caso em que o estado do gato é uma superposição de estados ou que a posição de uma partícula é uma superposição de posições possíveis (fiquemos com o caso do gato), ambas "vivo" e "morto" são falsas, pois o seu estado não é qualquer desses, mas descrito pela soma vetorial, por um vetor como (2), como vimos acima (o mesmo ocorre com as posições, obviamente).

Podemos definir semanticamente uma choice negation ou, como preferimos denominar, uma negação quântica do seguinte modo. Suponha que dispomos de uma linguagem adequada, digamos de primeira ordem, contendo um símbolo de negação $\neg q$. Seja $V$ o conjunto dos valores de verdade, sendo $V=D \cup N$, com $D \cap N=\emptyset$. O conjunto $D$ é o dos valores distinguidos, e $N$ o dos valores não distinguidos; se quisermos, podemos tomar $V=\{0,1\}$, com $D=\{1\}$ e $N=\{0\}$. Se $\alpha$ é uma fórmula e $v$ é uma valoração, ou seja, uma função $v: \mathcal{F} \mapsto V$, onde $\mathcal{F}$ é o conjunto das fórmulas, pomos:

$$
v(\neg q \alpha) \in D \text { implica } v(\alpha) \in N .
$$

Como a recíproca não vale necessariamente, fica claro que tanto $\alpha$ como $\neg_{q} \alpha$ podem assumir valores não distinguidos (serem ambos "falsas") sem que tenham que assumir também valores distinguidos - um estudo mais detalhado é feito em Krause \& Gracher, a aparecer.

Baseados em uma interpretação advinda do Quadrado de Oposições, Arenhart e este autor deram uma interpretação para a choice negation em termos de contrariedade (Krause \& Arenhart 2016), algo já adiantado em Priest \& Routley (1989), Béziau (2006), apesar desses autores não terem se referido à mecânica quântica especificamente. Se uma proposição e sua negação são vistas como contrárias e não como contraditórias (negação exclusiva, representada nas diagonais do quadrado), a intuição da choice negation é obedecida: ambas podem ser falsas, sem que possam ser ambas verdadeiras (no caso do gato, a terceira situação ocorre quando o estado é descrito por uma superposição de estados).

Nota-se observando o quadrado que, devido à sub-alternação, $\neg_{q} \alpha$ implica $\neg \alpha$, como lógicos quânticos dizem ser o caso (Aerts et al. 2000); a demonstração pode ser vista em Krause \& Gracher (a aparecer). ${ }^{19}$

19 A sub-contrariedade é vista como uma outra negação, dita negação paraconsistente. 


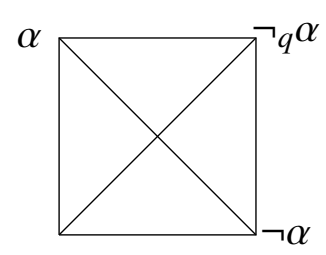

Fig. 2 - O quadrado das oposições exibindo a contrariedade. Proposições contrárias, como $\alpha$ e $\neg_{q} \alpha$ podem ser ambas falsas, mas não podem ser ambas verdadeiras. A negação "clássica" de $\alpha$ é indicada por $\neg \alpha$, sua contraditória.

Com efeito, as sentenças $A$ (o material radioativo não decaiu, gato vivo) e $B$ (o material decaiu, gato morto) são contrárias, e não contraditórias. A negação de "gato vivo" não é "gato morto" e vice-versa, pois "não estar vivo (morto)" pode significar que está em um estado que é uma superposição desses dois estados, ou seja, como advogou van Fraassen, "não estar vivo" pode não equivaler a "estar morto" (a negação exclusiva de "estar vivo"). Insistindo, isso indica que ambas podem ser falsas, mas não podem ser ambas verdadeiras.

No algebrismo quântico, os vetores $A$ e $B$ da figura (1) são ortonormais (ortogonais e unitários) e a ortogonalidade é o que se chama de uma involução, e semanticamente não coincide com a negação da lógica clássica (Beltrametti \& Cassinelli op.cit, p.221; Aerts et al. 2000). Em outros termos, se isso faz sentido, negar o estado $A$ significa tomar qualquer estado distinto de $A$, mas não necessariamente $B$. O mesmo se pode dizer de $B$.

\section{Em dois lugares ao mesmo tempo?}

Voltemos ao caso da posição de uma partícula, agora com um pouco mais de detalhes. Como dissemos acima, muitos textos falam que, previamente a uma medição, uma partícula pode estar em dois ou mais lugares ao mesmo tempo, o que também é equivocado. Da mesma forma que no caso do gato, uma partícula não tem posição em sentido clássico, mas estados-posição, se podemos chamar assim. Aliás, a suposição usual pressupõe que uma partícula seja algo como uma pequena bolinha que estaria "por aí", no caso, em vários lugares ao mesmo tempo. A mecânica quântica não corrobora essa interpretação (como vimos insistindo, essa disciplina nada afirma sobre a natureza das entidades). Ou seja, antes do vetor que descreve sua posição colapsar por causa de uma interação (medição), o que há é um vetor que também é uma superposição de todos os estados (posições) possíveis, e os quadrados dos coeficientes dessa combinação linear indicam a probabilidade do vetor colapsar naquele estado associado ao coeficiente. Assim, se um vetor de estado é algo como (não necessariamente expressando posições)

$$
E=a A+b B+c C+d D,
$$

após o colapso o estado reduz-se a $A, B, C$ ou $D$ respectivamente com probabilidades $a^{2}, b^{2}, c^{2}$ e $d^{2}$. Portanto, nada de duas ou mais posições ao mesmo tempo antes ou depois da medição.

Note bem - trabalhamos, como na combinação linear acima, com amplitudes de probabilidades, cujos quadrados fornecem as probabilidades estrito senso. Isso pode ser (como geralmente é) interpretado como indicando que alguma coisa existe previamente à medição, e que sua localização só será determinada após a medição; antes, só temos probabilidades. Esse discurso, no entanto, não é adequado pois sugere que exista algo (uma bolinha?) "escondido", o que não parece ser o caso. Voltaremos a esse ponto mais abaixo. 


\section{Os orbitais e o uso de figuras}

Outro equívoco, relacionado com o que se acabou de dizer, vem do uso de imagens e de sua interpretação. Ocorre em física o mesmo que ocorre em matemática: figuras têm unicamente papel heurístico, não podendo ser utilizadas para se fazer inferências, exceto em linguagens propositadamente alteradas para isso, como em teoria de categorias e nos diagramas de Feynman.

No entanto, em muitos livros de química vemos desenhos dos orbitais como áreas borradas e usualmente se diz serem as regiões onde há maior probabilidade de se encontrar o elétron. Outro equívoco, porque passa a idéia de que o elétron seria uma coisinha como uma pequena bola escondida naquela fumaça (veja a Figura 3 abaixo). Não é nada disso; o elétron não tem uma imagem clássica. A região sombreada corresponde a uma representação gráfica do orbital $1 s$ de um átomo de hidrogênio, mas de modo mais preciso corresponde ao que seria a imagem da função de onda normalizada $\psi_{100}$ que tem como números quânticos $l=1, m=n_{l}=0$ - para detalhes, Griffiths (2011), §4.2. O quadrado dessa função, integrada sobre um volume $d V$ indica, como se diz, "a probabilidade de se encontrar o elétron no dado volume". Esse discurso, como vimos insistindo, é dúbio. Trata-se de um nível de energia para o átomo: nada é dito sobre o formato do elétron, muito menos que ele é ou deve ser algo "escondido" nessa região. Como diz Griffiths (op. cit., p.116), a região é uma superfície de uma densidade de probabilidade constante. É isso o que temos; qualquer inferência sobre a natureza do elétron é nossa, faz parte da interpretação.

Dizer que o elétron é a região toda também não resolve o problema, pois estaríamos identificando algo supostamente físico (o elétron) com uma abstração matemática (a função de onda ou eventualmente - e com maior equívoco ainda — com sua representação gráfica) ${ }^{20}$

A natureza dos objetos quânticos é algo discutível, mas aceita-se que se necessita de uma ontologia que não tem nada a ver com a clássica (em Krause et al. (2012), damos alguns detalhes do que seria uma ontologia quântica em comparação com uma ontologia clássica).

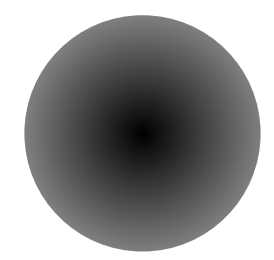

Fig. 3 - Esquema do orbital $1 s$. No discurso comum, a área mais escura é aquela "onde é mais provável encontrar o elétron".

20 A analogia com um conjunto difuso igualmente não é boa porque os elementos desses conjuntos ainda são objetos dotados de identidade (ver abaixo), havendo somente uma ignorância em sentido epistemológico sobre onde eles estão localizados. No caso dos elétrons, a situação é outra; não temos imagens dessas coisas, mas unicamente sua descrição matemática, dada pela função de onda que está concentrada em torno do núcleo mas não tem ponto fronteira. (Um ponto fronteira de um conjunto é um elemento do conjunto tal que qualquer círculo - para ficarmos no plano - com centro no ponto tem tanto elementos do conjunto como elementos de fora do conjunto). 


\section{As duas fendas}

Outro erro conceitual, na opinião deste autor, ocorre quando se tenta "explicar" o famoso experimento das duas fendas. É comum o discurso de que, quando ambas estão abertas, a partícula (o objeto quântico, seja lá o que ele for) passa pelas duas fendas ao mesmo tempo, e que quando eles são enviados um a um, "eles interferem com eles mesmos", isso para que se possa explicar o fenômeno da interferência. ${ }^{21}$ Nada disso é dito pela mecânica quântica. Novamente, antes da partícula chegar ao anteparo, quando ocorre o colapso, o que temos é um estado de superposição dos estados "passar pela fenda 1" e "passar pela fenda 2", mas isso não indica que temos de uma só vez as duas situações isoladamente. De novo, é preciso constatar que a superposição "|passar pela fenda 1$\rangle+$ |passar pela fenda 2$\rangle "$ não é a conjunção de suas sentenças, mas uma soma vetorial. A mecânica quântica não fala nada da partícula antes de ela alcançar o anteparo. Isso é coisa da interpretação dada, que, de novo pensa a partícula como uma pequena bolinha.

Com efeito, há algumas coisas que a mecânica quântica nos conta e que vão de encontro à concepção usual que temos dos objetos físicos. Algumas delas são as seguintes, e se referem ao elétron e ao experimento das duas fendas quando padrões de interferência são observados. Nesse caso, são falsas as afirmativas seguintes: a) o elétron passa só pela fenda 1 b) o elétron passa só pela fenda 2 c) o elétron passa pelas duas fendas d) o elétron não passa por fenda alguma.

As razões são, de modo breve, as seguintes: uma vez que se verificou que o anteparo apresenta franjas de interferência (veja a Figura 4), a) e b) têm que ser falsas, pois se uma delas fosse verdadeira (o que implicaria que a outra seria falsa), o padrão observado não seria o de interferência. c) não pode ser verdadeira pois não se pode "quebrar" uma partícula em duas, exceto, de certo modo, na mecânica Bohmiana, onde cada partícula é "guiada" por uma onda, assim havendo as duas coisas acopladas (veja a seção ()). A sentença d) também não pode ser verdadeira, pois verificou-se que há registro no anteparo; logo, algo passou. O problema, como o vemos, é que não estamos lidando com uma entidade como aquelas descritas pela física clássica e que se conforma com os objetos de nossa intuição.

Do ponto de vista lógico, isso traz um problema, que discutiremos na seção 9. Os lógicos quânticos, como em Aerts et al. (2000), creem no entanto que a conjunção nas lógicas quânticas se comporta como a conjunção da lógica clássica. Aceitando essa premissa, como explicar a discrepância apresentada pelos quatro itens acima? "Classicamente", eles não poderiam ser todos violados. Nossa explicação é a de que a negação das quatro possibilidades se dá no nível metateórico, no nível da interpretação, e não na linguagem objeto. Se não houvesse discrepância entre os níveis metateórico (das interpretações) e teórico (do formalismo matemático), certamente não seria possível atribuir a um mesmo formalismo interpretações distintas, mas apenas uma intererpretação "necessária". ${ }^{22}$

${ }^{21}$ Não vamos revisar o experimento aqui. Uma descrição excelente, ainda que contendo o vício para o qual estamos chamando a atenção, pode ser vista em Kumar (2009), p.267ss.

22 Em French \& Krause (2006), oferecemos duas interpretações para o formalismo da mecânica quântica não relativista; uma delas considera os objetos quânticos como indivíduos, ao par com seus correlatos na física clássica; a outra os toma como não-indivíduos, entidades para as quais o conceito usual de identidade não se aplica. Ademais, mostra-se que a física não nos permite determinar qual interpretação é a "correta". Como dizemos naquele livro, a metafísica fica subdeterminada pela física. 
Por enquanto, como podemos entender uma situação como essa? O fato é que, usando nossos cânones "clássicos", com os quais estamos acostumados, não temos como. A situação é completamente nova, completamente quântica. O elétron não é algo que possa ser comparado a um objeto macroscópico qualquer, e seu comportamento não pode ser descrito pela física clássica, como tentamos fazer quando imaginamos que uma dentre as quatro afirmativas acima tem que ser verdadeira. Atualmente, experimentos com as duas fendas têm sido realizados com coisas "grandes" para os padrões quânticos, como com moléculas contendo 810 átomos! (Eibenberg et al. 2013) e os padrões de interferência típico de ondas têm sido observados. ${ }^{23}$

No experimento das duas fendas, o que a mecânica quântica nos mostra são duas alternativas de situações que podem ser observadas no anteparo; (1) uma situação envolvendo franjas de interferência e (2) apenas uma dentre duas bandas de pontos, conforme a figura abaixo, dependendo de qual fenda esteja fechada. Porém, nada sabemos sobre o que há entre a fonte e o anteparo.

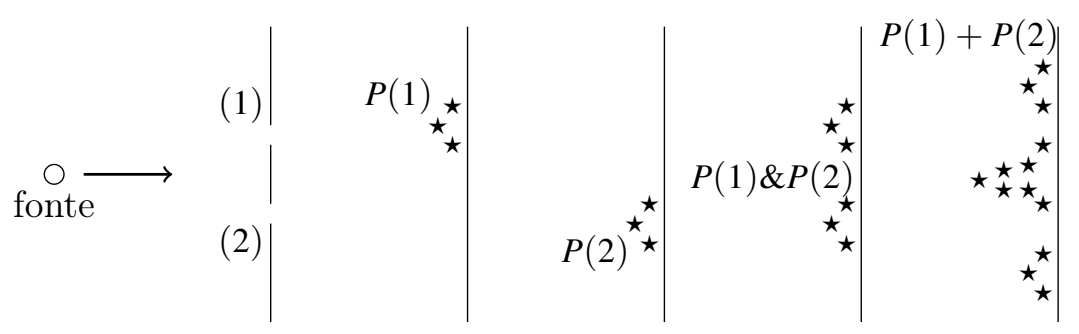

Fig. 4 - Esquema ds resultados obtidos no experimento das duas fendas. O padrão $P(1)$, é observado quando somente (1) está aberta; o padrão $P(2)$ ocorre quando apenas (2) está aberta. O padrão $P(1) \& P(2)$ seria o esperado para as duas fendas abertas, mas não é o que ocorre. Pelo contrário, o que ocorre é $P(1)+P(2)$, um padrão de interferência. ${ }^{24}$

Com efeito, a interpretação é nossa. Como dito na Introdução, sempre que enfrentamos uma situação nova à qual queremos dar uma explicação, iniciamos com o que temos às mãos. No caso, a física clássica e nosso conhecimento dos comportamentos ondulatório e de partículas, e na falta de coisa melhor, é essa a associação que fazemos. Assim, baseados em nossos conhecimentos de física clássica e do senso comum, associamos à primeira alternativa a um comportamento do tipo ondulatório, enquanto que a segunda apresenta um comportamento do tipo de partículas. No entanto, nada disso é dito pela mecânica quântica, que nos apresenta apenas os resultados matemáticos. Tudo o que a mecânica quântica nos dá são as duas alternativas, só isso. Com efeito, "ser onda" e "ser partícula" não são estados de sistemas quânticos, e nunca se vê uma superposição de "ser partícula" e "ser onda", mas a função de onda (vetor de estado) é uma superposição de "passou pela fenda 1" e "passou pela fenda 2".

Em 1970, o grande físico John Archibald Wheeler inventou uma analogia interessante. Comparou a situação com um dragão de fumaça, do qual conhecemos o rabo (o que acontece na fonte, por exemplo que tipo de radiação estamos emitindo, se elétrons ou

23 Em Pessoa Jr. (2006), capítulo XXXI, §8, comenta-se sobre esse tipo de fenômeno com outros objetos "macroscópicos". Em Zeilinger (2005), comenta-se o experimento das duas fendas feito com objetos como fulerenos, ou moléculas bolas de futebol, que são moléculas compostas de 60 ou 70 átomos de carbono, algo considerado "grande" para os padrões quânticos.

24 No formalismo matemático, isso é explicado quando se toma o quadrado da função de onda (que fornece a probabilidade): $\|P(1)+P(2)\|^{2}=\|P(1)\|^{2}+\|P(2)\|^{2}+2 \operatorname{Re}\langle P(1) \mid P(2)\rangle$, sendo $2 \operatorname{Re}\langle P(1) \mid P(2)\rangle \mathrm{o}$ termo de interferência, o dobro da parte real do produto interno entre $P(1)$ e $P(2)$. 
fótons), e a cabeça, ou seja, os resultados observados, como as situações $P(1), P(2)$ ou $P(1)+P(2)$ acima, e mais nada: tudo entre a cabeça e o rabo é fumaça, não sabemos como é! Imaginar o corpo do dragão é coisa nossa. No entanto, insistamos, não podemos imaginar "qualquer coisa". Por exemplo, supor que no interior da fumaça o sistema esteja partilhando de estados contraditórios é equivocada pelos motivos já expostos.

\section{Mach-Zehnder}

Situação semelhante ocorre com o experimento Mach-Zehnder, quando é de novo errado afirmar que a "partícula" percorre os dois caminhos ao mesmo tempo (Figura 5). A mecânica quântica nada fala do que acontece com o sistema físico antes de ele alcançar um dos receptores. Qualquer conclusão a esse respeito é coisa da interpretação. Se os dois caminhos $A$ e $B$ estiverem disponíveis, o que ocorre se nenhum "observador" for colocado em um deles (de modo que se possa conhecer qual caminho o objeto percorreu), a interpretação intuitiva e baseada na física clássica, que como vimos insistindo Dirac considerava equivocada, é a de que a partícula passou por ambos os caminhos, caso em que toda a radiação é detectada no receptor 1, e nenhuma no receptor 2. E isso ocorre mesmo se for emitida uma partícula de cada vez. Mas se um dos caminhos estiver interrompido ou sendo "observado", constata-se que $50 \%$ da radiação é detectada em cada receptor. Uma vez que se emite uma partícula por vez (estando ambos os caminhos sem detetores), só se pode pensar que a partícula percorreu ambos os caminhos de uma só vez, diz a interpretação comum.

Mas, como pode uma partícula se dividir em duas se não há "meia partícula"? Isso não faz sentido; não sabemos o que ocorre entre o rabo do dragão (a fonte) e a sua cabeça (os receptores). Não temos como explicar isso coerentemente em termos daquilo com o que estamos acostumados. Não há qualquer analogia "clássica" que possamos fazer. Trata-se de um fenômeno tipicamente quântico, sem qualquer análogo na física clássica, para a qual tentamos reduzir praticamente tudo para alcançar uma explicação. Uma descrição ainda intuitiva, porém mais detalhada, pode ser vista em Krause (2017), cap.6. Saliente-se que o comum é aceitar que a nossa ignorância acerca do corpo do dragão não é de natureza epistemológica, pois isso nos faria ter que aceitar a existência de alguma forma de variável oculta, mas (uma vez que afastemos o instrumentalismo) de natureza ontológica. Colocando em termos diretos, o bicho é outro.

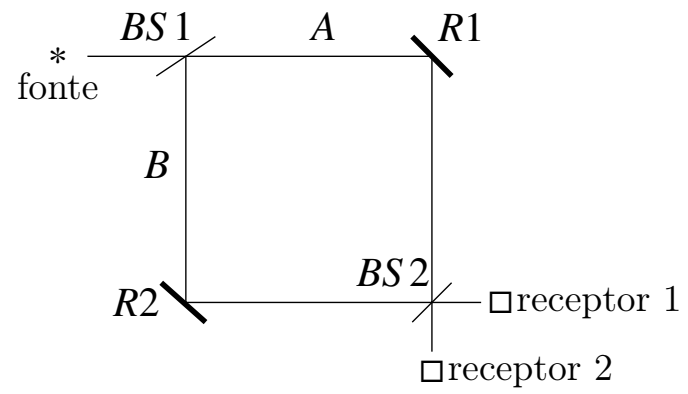

Fig. 5 - O interferômetro Mach-Zehnder. Se os dois caminhos $A$ e $B$ estiverem disponíveis, toda a radiação é observada no receptor 1 , e nenhuma no receptor 2 . Intuitivamente, isso indica que a radiação passou por ambos os caminhos. Um beam splitter $(B S)$ é um dispositivo que, em termos clássicos, divide o raio de luz ou outra radiação eletromagnética, fazendo-a percorrer os caminhos disponíveis. $R 1$ e $R 2$ indicam refletores. 


\section{A identidade}

Outro conceito problemático e sobre o qual muitos equívocos são postos é o de identidade. A tendência dos filósofos e cientistas em geral é não aceitar que possa haver qualquer questionamento sobre esse conceito, e que ele é necessário (Bueno 2014). Claro que primeiramente necessitamos saber do que estamos falando.

Temos uma noção intuitiva de identidade quando aceitamos que todos os objetos podem ser identificados, pelo menos em princípio, como sendo aqueles objetos com os quais já tivemos alguma experiência anterior; o computador à minha frente é o mesmo que o que estava à minha frente ontem. Cada um desses objetos é único e diferente de todos os outros. Se necessário, fazemos uma marca em cada um deles, colocamos-lhes algum rótulo identificador, o que nos permitirá discernir mesmo entre objetos muito semelhantes, como dois comprimidos de uma caixa de remédio. Os objetos que nos cercam são indivíduos, são vistos como unidades, têm individualidade, podem ser individualizados, isolados. Os conceitos de identidade, individualidade e individuação são geralmente tratados como sinônimos, mas apresentam diferenças, discutidas em Arenhart, Bueno \& Krause (a aparecer), porém não repetidas aqui.

Há bastante tempo, David Hume colocou dúvidas sobre essa concepção intuitiva: a tendência que temos de pensar que um objeto possa permanecer o mesmo, para o qual atribuímos uma identidade, dever-se-ia a uma conexão que fazemos entre causa e efeito (constância em nossas percepções), mas não temos qualquer garantia de que ele não sofreu mudanças, mesmo que haja semelhanças que se mantenham (Hume 1985, p.74, e passim). Assim, se considerarmos que a noção usual de identidade, dita identidade leibniziana, pressupõe que nenhum objeto pode ter exatamente os mesmos atributos que qualquer outro, quando sofre mudanças, como avançar na idade, o objeto já não seria mais o mesmo, idêntico ao anterior. No tocante às entidades quânticas, Schrödinger disse coisa semelhante:

"quando um objeto familiar entra novamente em nosso campo de percep-
ção, é usualmente reconhecido como uma continuação de aparecimentos
prévios, como sendo a mesma coisa. A permanência relativa de peças
individuais de matéria é a característica mais importante tanto da vida
diária quanto da experiência científica. Se algo familiar, digamos uma
moringa de barro, desaparece de nossa sala, teremos quase a certeza de
que alguém a carregou. Se após um certo tempo ela reaparece, pode-
remos ficar em dúvida se é a mesma moringa ou não - objetos frágeis
em tais circunstâncias frequentemente não são. Podemos não ser capazes
de decidir a questão, mas devemos não ter duvida de que a questionável
similaridade tem um significado indisputável - a de que há uma res-
posta não ambígua à nossa pergunta. Tão certa é a nossa crença na
continuidade das partes não observadas das sequências!" (Schrödinger
1998). ${ }^{25}$

Com efeito, na tentativa de encontrar o motivo das coisas nos parecerem indivíduos, somos levados à procura de algum Princípio de Individuação. A literatura filosófica nos apresenta dois grandes grupos de teorias a esse respeito, as teorias de substrato e as teorias

25 Para uma comparação mais detalhada entre esses dois autores sobre a identidade de objetos, ver Krause \& Becker Arenhart (2006). 
de pacotes de propriedades. Ainda que possam haver pequenas variações no âmbito de cada uma delas, as primeiras se assentam na hipótese de que uma entidade como um objeto físico não é apenas constituído pelas suas características (propriedades e relações), como apregoam as segundas, mas que haveria algo para além das propriedades que conferiria a individuação a uma entidade. A natureza desse "algo" permanece em aberto (ver Locke (1995), Livro II, cap.23). Em (2008), Paul Teller afasta essa possibilidade com relação aos objetos quânticos; para ele, no mundo quântico não há substrato ou haecceities de qualquer tipo.

Porém, como veremos a seguir, a mecânica quântica nos fornece argumentos para que possamos questionar essa noção intuitiva dada por alguma teoria de pacotes de propriedades (mais abaixo). Portanto, parece surpreendente que ainda hoje, quando vivemos em um tempo em que lógicas divergentes da lógica clássica são comuns, algumas das quais questionando princípios e conceitos atávicos, como o terceiro excluído ou a lei da contradição, ainda haja um taboo relativamente ao conceito de identidade. Para muitos, como já antecipado acima, esse conceito é inquestionável, necessário para toda e qualquer forma de expressão racional (Bueno 2014). Que isso não é assim, tem sido apontado em alguns artigos (ver, especialmente, Krause \& Arenhart 2018). ${ }^{26}$

As entidades quânticas como átomos, elétrons e prótons não podem ser inspecionados visualmente, mesmo que para isso utilizemos microscópios muito potentes - tudo o que teremos serão representações dessas coisas, assim como temos representações (simulações) de fractais em uma tela de computador, apesar de que fractais são coisas não computáveis. Não devemos nos iludir, portanto, com as pretensas imagens de átomos que encontramos na internet e em revistas de divulgação. Essas entidades nos são dadas pelas leis das teorias (de pacotes de propriedades) que utilizamos. Por exemplo, um elétron é algo que tem massa $m=9,1 \times 10^{-28} g$, carga elétrica $e=4,8 \times 10^{-10}$ e.s.u. ${ }^{27}$ e $\operatorname{spin}=1 / 2$ (em unidades de $\hbar$ ). Aquilo que satisfaz essas condições é um elétron; são características que podemos chamar (em sentido aristotélico) de essenciais. Se algo tiver a mesma carga elétrica e o mesmo valor de spin, mas massa igual a $1,9 \times 10^{-25} \mathrm{~g}$, não é mais um elétron, mas um muon. Não há elétrons mais gordos ou mais magros; se mudam-se essas características, mudam-se as entidades. Ademais, todos os elétrons têm essas mesmas propriedades, este aqui na ponta do meu dedo e aquele lá em Antares. Sua distinção é dada pela localização, mas mesmo isso apresenta problemas, como apontado em Krause (2018). ${ }^{28}$

Em resumo, o que se passa é o seguinte. Se queremos tratar de um sistema com dois objetos quânticos de mesmo tipo (tendo as mesmas propriedades "essenciais"), como os dois elétrons referidos, devemos fazer isso por meio de uma função que é simétrica ou anti-simétrica relativamente à permutação dos nomes dessas partículas (os rótulos que somos obrigados a utilizar por causa das limitações de nossa linguagem como "partícula 1" e "partícula 2"), como no vetor (2). Se a tal função (dita função de onda) for simétrica, uma troca de "partícula 1" por "partícula 2" e vive-versa não a altera, mas ela troca de

${ }^{26}$ Outros pensadores do início do século XX colocaram questionamentos relativamente a esse conceito, mas não trataremos disso aqui, deixando essa constatação para um trabalho futuro.

27 ESU indica o sistema de unidades eletrostáticas.

28 Se formos descrever o elétron que está no meu dedo pela função de onda (vetor de estado) $\psi_{D}$ e o que está em Antares por $\psi_{A}$, quando consideramos o sistema conjunto, a função de onda será algo como a função (2), simplificadamente (exceto por constantes) $\psi_{A B}=\psi_{A}+\psi_{B}$, uma superposição das duas funções. E, nesse caso, não termos mais como discernir entre os elétrons. 
sinal se a função for anti-simétrica (como no caso dos elétrons). Isso na verdade não importa, porque a função de onda (chamemo-la de $\psi$ ) não tem qualquer papel ontológico. Apenas o seu quadrado $|\psi|^{2}$ tem significado físico, representando uma probabilidade. Ou seja, não falamos desse elétron (por meio de uma função de onda 1) e daquele elétron (por meio de uma função de onda 2). O que fazemos para nos referir a ambos os elétrons é usar uma função anti-simétrica (no caso de férmions) que não distingue esse sistema daquele sistema. Não há identidade no sentido clássico.

9.1 Observação sobre a mecânica de Bohm. Como acima nos referimos à mecânica bohmiana, é conveniente falar algo sobre ela. É discutível se a versão da mecânica quântica devida a David Bohm constitui uma formulação alternativa ou se é uma teoria diferente. O fato é que a metafísica associada a essa mecânica é semelhante à clássica. Os sistemas físicos mais elementares são uma associação entre uma partícula e uma onda piloto, que "guia" a partícula. A partícula tem características "clássicas", tendo um comportamento semelhante àquelas descritas pela física clássica: elas têm identidade, trajetórias bem definidas, dentre outras coisas. No experimento das duas fendas, assume-se que a partícula passa por uma das duas fendas e a onda passa por ambas, e é essa onda que produz o fenômeno de interferência. A mecânica bohmiana, ao que tudo indica, é empiricamente equivalente à mecânica quântica "usual", mas isso também é discutível. As partículas, como na física clássica, têm posições bem definidas a cada instante de tempo, e mesmo suas trajetórias podem ser seguidas por meio de medições fracas, que não interferem na trajetória das partículas. ${ }^{29}$

O fato é que, como temos visto, não se pode observar a partícula passando por uma fenda; se isso for feito, o padrão de interferência desaparece. Saliente-se que o resultado observado no experimento não depende da teoria considerada. Assim, a descrição acima de que a partícula passa por uma das fendas e a onda por ambas é apenas uma suposição, mais uma, mas a intuitivamente a mais consoante com a teoria de Bohm.

\section{E a lógica?}

Em 1936, G. Birkhoff e J. von Neumann estenderam algumas idéias avançadas por von Neumann em um livro de 1932. Nesse trabalho, os dois advogaram que considerando os estados dos sistemas quânticos como superposições de autovetores de operadores hermitianos sobre um adequado espaço de Hilbert, os quais representam os observáveis, resulta uma álgebra de subespaços desse espaço que fere a distributividade da conjunção (interseção de subespaços) relativamente à união (mais precisamente, ao espaço gerado pela união de subespaços), fazendo com que esses "conectivos" destoem daqueles da lógica clássica; para detalhes, ver o cap. 8 de Jammer (1974), Aerts et al. (2000). A partir da década de 1960, esse campo começou a ser estudado sistematicamente, caracterizando o que ficou denominado de Lógica Quântica (para históricos, ver o capítulo 8 de Jammer (1974), Beltrametti \& Cassinelli op.cit., de Ronde et al. 2018).

Muitas lógicas quânticas foram desenvolvidas a partir daí (Dalla Chiara et al. 2004, Svozil 2005, Pavičić \& Megill 2009). No entanto, prosseguiram como um estudo paralelo, notadamente nos dias de hoje, quando a área tornou-se quase que totalmente o estudo

${ }^{29}$ Ocorre algo parecido como quando você arremessa uma pedra e vê a sua trajetória no ar; os fótons que incidem sobre a pedra causam tão pouca modificação em sua trajetória que ela pode ser observada. Mas isso já extrapola os nossos objetivos; o leitor interessado pode ver uma interessante defesa da teoria de Bohm, explicando as medições fracas inclusive, em Bricmont 2016, pp.135-6. 
da computação quântica, sem que houvesse uma fundação sistemática da teoria quântica tendo uma dessas lógicas como lógica subjacente. Com efeito, se olharmos um livro qualquer de mecânica quântica ou mesmo de suas extensões à mecânica quântica relativista, não encontramos qualquer lógica quântica sendo previamente descrita. A lógica, bem como a matemática, continua sendo a clássica. Isso certamente funciona bem do ponto de vista do físico mas, como estamos vendo, apresenta uma bela quantidade de problemas dos pontos de vista conceitual e filosófico.

Uma tentativa radicalmente diferente foi proposta por Domenech et al. (2008) e (2010). Nesses trabalhos (ver também Krause \& Arenhart 2018b), elaborou-se uma formulação da teoria dos espaços de Fock, que fundamentam a teoria quântica das partículas sem interação, em termos de quase-conjuntos, uma teoria matemática que permite a consideração de entidades destituídas de individualidade, como parecem ser os objetos quânticos na visão de muitos. Nesse caso, trata-se sem dúvida de uma fundamentação dessa disciplina utilizando-se uma lógica distinta da clássica.

O tema da lógica da mecânica quântica, em distinção à lógica quântica, permanece atual e relevante. Se formos levar em conta alguma interpretação particular, como aquela que vê os objetos quânticos como entidades destituídas de identidade em sentido clássico, uma nova base matemática seria recomendável. Esse assunto é discutido particularmente em Krause (2018b).

\section{Paraconsistência}

Para não sermos completamente negativos com relação à possibilidade de se utilizar uma lógica paraconsistente em mecânica quântica, salientaremos dois pontos em adição ao que já se disse acima na nota de rodapé 12. Em da Costa e Krause (2006), usamos uma lógica paraconsistente, denominada de lógica paraclássica para acomodar o conceito de complementaridade, ao qual demos uma interpretação. Não discutiremos esse caso aqui. O que queremos sugerir é que talvez se possa utilizar essa mesma lógica para dar conta de casos como o do gato. Suponha que adotemos a interpretação dos muitos mundos (Wallace 2012). De acordo com essa interpretação, depois da medição o mundo de parte em dois (ou mais), um no qual o gato está vivo e outro no qual ele está morto. Esses dois mundos existem, são reais, mas não se comunicam. Ou seja, temos "gato vivo" e "gato morto", mas não a sua conjunção; a lógica paraclássica não é adjuntiva, ou seja, de duas fórmulas $\alpha$ e $\beta$ nem sempre se pode formar a sua conjunção $\alpha \wedge \beta$. Assim, poderíamos ter "gato vivo" e "gato morto", porém não em um mesmo mundo, como já dito na nota referida acima. Adiantaria em algo? Não creio. O importante é que, mesmo nessa situação, antes da medição a situação continua exatamente como descrita acima, sem contradição. 


\section{Referências Bibliográficas}

[1] Aerts, D., D' Hondt, E. and Gabora, L. (2000), Why the logical disjunction in quantum logic is not classical. Foundations of Physics, 30 (9): 1453-1480.

[2] Albert, D. Z. (1994), Quantum Mechanics and Experience. Harvard Un. Press.

[3] Arenhart, J. R. B. \& Krause, D. (2016), Contradiction, Quantum Mechanics, and the Square of Opposition. Logique et Analyse 59 (235): 301-15.

[4] Arenhart, J. R. B., Bueno, O. and Krause, D. (2019) Making sense of non-individuals in quantum mechanics. In O. Lombardi, Fortin, S., López, C. and Holik, F. (eds.), Quantum Worlds. Different Perspectives about the Ontology of Quantum Mechanics. Cambridge: Cambridge Un. Press: 185-204.

[5] Baggott, J. (2013), The Quantum Story: A History in 40 Moments. Oxford: Oxford University Press.

[6] Béziau, J. -Y. (2006), Paraconsistent logic! Sorites 17: 17-25.

[7] Birkhoff, G. and von Neumann, J. (1936), The logic of quantum mechanics. Annals of Mathematics 37: 823-43.

[8] Bricmont, J. (2016), Making Sense of Quantum Mechanics. Springer.

[9] Bueno, O. (2014), Why identity is fundamental. American Philosophical Quarterly, 51, p.325-32.

[10] Chibeni, S. S. (1997), Aspectos da Descrição Física da Realidade. Campinas, Centro de Lógica, Epistemologia e História da Ciência (Coleção CLE 21).

[11] da Costa, N. C. A. and Krause, D. (2006), The logic of complementarity. In J. van Benthem, G. Heinzmann, M. Rebushi and H. Visser (eds.), The Age of Alternative Logics: Assessing Philosophy of Logic and Mathematics Today. Springer: 103-120.

[12] da Costa, N. and de Ronde, C., 2013, The Paraconsistent Logic of Quantum Superpositions. Foundations of Physics 43, 845-858.

[13] Dalla Chiara, M. L., Giuntini, R. and Greechie, R. (2004), Reasoning in Quantum Theory: Sharp and Unsharp Quantum Logics. Dordrecht: Kluwer Ac. Pu. (Trends in Logic, 22).

[14] Dirac, P. A. M. (1967), The Principles of Quantum Mechanics. Cambridge: Cambridge Un. Press.

[15] Domenech G., Holik, F. \& Krause, D. (2008), Q-spaces and the foundations of quantum mechanics. Foundations of Physics 38 (11): 969-994.

[16] Domenech, G., Holik, F, Kniznik, L. \& Krause, D. (2010), No labeling quantum mechanics of indiscernible particles. International Journal of Theoretical Physics 49 (12): 3085-3091.

[17] Fine, A. (1986), The Shaky Game: Einstein, Realism, and the Quantum Theory. Chicago: Chicago Un. Press.

[18] Folse Jr., H. J. (1986), Complementarity and scicntific realism. In Weingartner, P. and Dorn, G. (Eds.), Foundations of Physics: A Selection of Papers Contributed to the Physics Section of the 7th Ibternational Congresso $f$ Logic, Methodology and Philosophy of Science. Vienna: Hölder-PichlerTemsky, pp.93-101.

[19] French, S. \& Krause, D. (2006), Identity in Physics: A Historical, Philosophical, and Formal Analysis. Oxford: Oxford Un. Press.

[20] Gilmore, R. (1998), Alice no País do Quantum: A Física Quântica ao Alcance de Todos. Rio de Janeiro: Zahar.

[21] Griffiths, R. (2011), Mecânica Quântica. 2a. ed., São Paulo: Pearson Prentice Hall.

[22] Hacking, I. (1983), Representing and Intervening. Cambridge: Cambridge Un. Press.

[23] Howard, D. A. (2017), Einstein's Philosophy of Science, The Stanford Encyclopedia of Philosophy (Fall 2017 Edition).

[24] Kanitscheider, B. (1992), Schrödinger's cat and the interpretation of quantum mechanics. In Götschid, J. et al. (eds.), Erwin's Schrödinger's World View. Dordrecht: Kluwer Ac. Pu., 41-51.

[25] Krause, D. (2017), Tópicos em Ontologia Analítica. São Paulo: Ed. UNESP. 
[26] Krause, D. (2019), Does Newtonian space provide identity to quantum systems? Foundations of Physics 24(2): 197-215.

[27] Krause, D. (2018b), Quantum mechanics, ontology, and non-reflexive logics. Pré-publicação, https: / /arxiv.org/abs/1802.03805

[28] Krause, D. and Arenhart, J. R. B. (2016), A logical account of quantum superpositions. In Aerts, D., de Ronde, C., Freytes, H. and Giuntini, R. (eds.), Probing the Meaning of Quantum Mechanics: Superpositions, Dynamics, Semantics and Identity. Singapore: World Scientific, pp. 44-59.

[29] Krause, D. and Arenhart, J. R. B. (2019), Is identity really so fundamental? Foundations of Science. 24(1): 51-71.

[30] Krause,D. \& Arenhart, J. R. B. (2018b), Presenting Non-reflexive Quantum Mechanics: Formalism and Metaphysics. Cadernos de História e Filosofia da Ciência 4 (2) Jan-Jun. 2016, pp. 59-91.

[31] Krause, D., Arenhart, J. R. B. and da Costa, N. C. A. (2012), Ontology and the mathematization of the scientific enterprise. Phainomeon (Revista de Fenomenologia) 25: 109-130.

[32] Krause, D. \& Becker Arenhart, J. R. (2006), Hume, Schrödinger e a individuação de objetos físicos. Revista Eletrônica Informação e Cognição 5 (2): 59- 71.

[33] Krause, D. and Gracher, K. G. C. (a aparecer), A comparison among three negations: classical, quantum, and paraconsistent: a case study involving possible paraconsistent objects.

[34] Kumar, M. (2009), Quantum: Einstein, Bohr and the Great Debate About the Nature of Reality. London: Icon Books.

[35] Locke, J. (1995), An Essay Concerning Human Understanding. London: Routledge.

[36] Pavičić, M. and Megill, N. D. (2009), Is quantum logic a logic? In Engesser, K., Gabbay, D. M. and Lehmann, D. Handbook of Quantum Logics and Quantum Structures. Amsterdam: Elsevier, 23-47.

[37] Pessoa Jr. O. (2003), Conceitos de Física Quântica, Vol. I. São Paulo: Livraria da Física.

[38] Pessoa Jr. O. (2006), Conceitos de Física Quântica, Vol. II. São Paulo: Livraria da Física

[39] Priest, G. and Routley, R. (1989), Systems of paraconsistent logic. In Priest, G., Routley, R. And Norman, J. (Eds.), Paraconsistent Logic: Essays on the Inconsistent. Munich: Philosophia, pp. 151186.

[40] de Ronde, C., Domenech, G. and Freytes, H. (2018), Quantum logic in historical and philosophical perspective. Internet Encyclopedia of Philosophy (https://www.iep.utm.edu/qu-logic/). Acesso em $20 / 11 / 2018$.

[41] Saunders, S. et al. (2010), Many Worlds? Everett, Quantum Theory, and Reality. Oxford: Oxford Un. Press.

[42] Schrödinger, E. (1957), What is an elementary particle? In Schrödinger, E., Science Theory and Man. London: George Allen and Unwin Ltd., pp. 193-223.

[43] Schrödinger, E. (1980), The present situation in quantum mechanics. Proceedings of the American Philosophical Society 124: 323-38. (original alemão de 1935).

[44] Styer, D. F. et al. (2002), Nine formulations of quantum mechanics. Am. J. Phys. 70 (3): 288-97.

[45] Schlosshauer, M. (2004), Decoherence, the measurement problem, and interpretations of quantum mechanics. Review of Modern Physics 76 Oct.: 1267-1305.

[46] Svozil, K. (2005), Quantum logic. A brief outline. ArXiv: quant-ph/9902042v2 31 Jul 2005.

[47] Teller, P. (1998), Quantum mechanics and haecceities. In Castellani, E. (Ed.), Interpreting Bodies: Classical and Quantum Objects in Modern Physics. Princeton: Princeton Un. Press, pp. 114-41.

[48] Van Fraassen, B. (1974), The labyrinth of quantum logics. In Cohen, R. S. and Wartofsky, M. W. (Eds.), Logical and Epistemological Studies in Contemporary Physics. Dordecht and Boston: D. Reidel (Boston Stidies in the Philosophy of Science, 13).

[49] Wallace, D. (2012), The Emergent Multiverse: Quantum Theory according to the Everett Interpretation. Oxford: Oxford University Press.

[50] Zeilinger, A. (2005), A Face Oculta da Natureza: O Novo Mundo da Física Quântica. Rio de Janeiro: Globo. 